\title{
Cardiac arrest in the operating room: what to think? About 4 cases and review of the literature
}

\author{
N. Jbili*, N. Jebbar, L. Bibiche, A. Diai, A. Maaroufi, K.Chekoura, A. Moqaddam, J. Laoutid, H. Kechna \\ Pole of anesthesia resuscitation and emergencies, Moulay Ismail Military Hospital, Meknes, Faculty of Medicine and Pharmacy Rabat, University Mohammed \\ V. Morocco
}

Submission: November 28, 2019; Published: December 12, 2019

*Corresponding author: Jbili N, Pole of anesthesia resuscitation and emergencies, Moulay Ismail Military Hospital, Meknes, Morocco

\section{Introduction}

Cardiac arrest in the operating theatre is a serious and dramatic incident, with an incidence of 5.6 per 10,000 procedures. The context of the operating theatre generates specificities in relation to the pre-hospital approach, both in terms of diagnosis and management. Under general anesthesia, the diagnosis and conduct of resuscitation is based on the monitoring that is already in place. Etiologies are primarily respiratory with the result of hypoxemia but also allergic and toxic accidents. Resuscitation is carried out in parallel with the control of the ventilation system. The prognosis is better due to the speed of diagnosis and resuscitation manoeuvres, which justifies prolonged resuscitation [1].

We report 4 observations of patients who had intraoperative cardiac arrest during a period from December 2015 to September 2019, which occurred in the operating theatre of the Moulay Ismail military hospital in Meknes.

\section{Observations}

\section{Obervation 1}

64-year-old patient, withno significant pathological anteriority, with a normal basic preoperative check-up, admitted to the operating theatre for a surgical treatment of an acute intestinal obstruction on volvulus of the sigmoid. A standard anesthetic monitoring was performed, Hemodynamic and respiratory parameters were correct. The induction was made by fentanyl, propofol and rocuronium adapted to weight, the entretiwas provided by the isoflurane. The hemodynamic parameters remained stable. Prior to the incision, the patient received an infusion of two grams amoxicilline-clavulanic acid. 10 minutes after the incision, blood pressure decreased from $125 / 85 \mathrm{mmHg}$ to $80 / 40$ without responding to ephedrine injection and filling with elevated ventilation pressures. The evolution was rapidly adverse by worsening the low blood pressure reaching up to $40 / 23 \mathrm{mmHg}$ and then settled a progressive bradycardia with wide QRSomplexes. Then an adrenaline syringe shoot was set up. Gradually the hemodynamic parameters stabilized with lower ventilation pressures and improved saturation. A biological assessment was carried out after the introduction of the VVC and having objectified a correct ionogram with retained kidney function and a normal troponin at $0.0052 \mathrm{~g} / \mathrm{l}$ (VN-INF 0.0350) and a negative CRP.

Biological monitoring of tropinin is summarized below (Table 1):

Table 1

\begin{tabular}{|c|c|c|c|c|c|}
\hline Time & H0 & H6 & H12 & J24 & J36 \\
\hline Troponin & 0.0052 & 0.7079 & 1.7406 & 0.8983 & 0.0873 \\
\hline
\end{tabular}

A labial edema settled 2 hours after the state of shock. And the interrogation with the family revealed a history of labial edema following the taking of NSAIDs. Electrocardiographic (ECG) recordings of the patient after $10 \mathrm{~min}$, at $\mathrm{H} 6$ and $\mathrm{H} 24$ did not reveal signs of ischemia or myocardial lesions, Transthoracic echocardiography did not objectice tokinetic disorders or valvulopathy and found apreserved ejection fraction. The patient was operated on 12 hours after this incident with invasive monitoring and without intraoperative complications

\section{Observation 2}

A 16-year-old patient with no particular history, who consults for lower limb edema set to a heart-compressing intrathoracic mass (Figure 1). She was admitted for exeresis of this mass The patient presented a stop at anesthetic induction following heart failure, recovered by internalcardiaq ue massageand adrenaline and anextreme bradycardia during pericardorrapheus also recovered. 


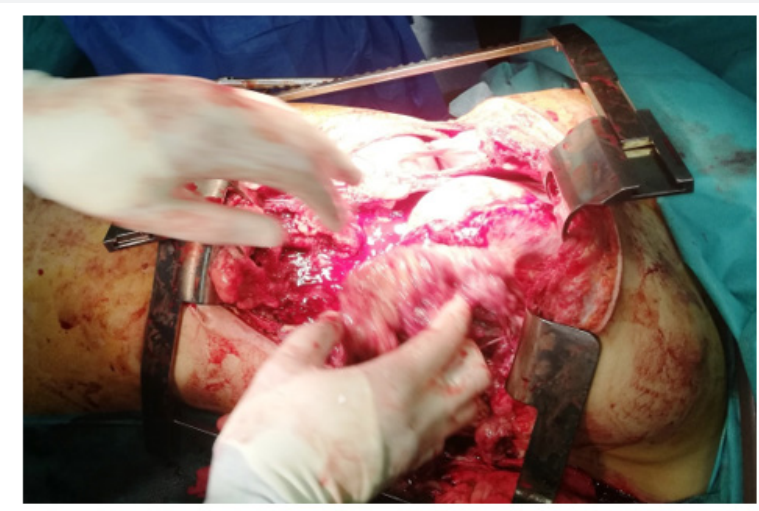

Figure 1: Intrathoracic mass compressing the heart.

\section{Observation 3}

58-year-old patient, with no particular history, admitted for exeresis of a large mediastinal tumor (Figure 2) who had intraoperative cardiac arrest following a rhythm disorder such as supraventricular tachycardia and haemorrhage following difficulty with surgical dissection.

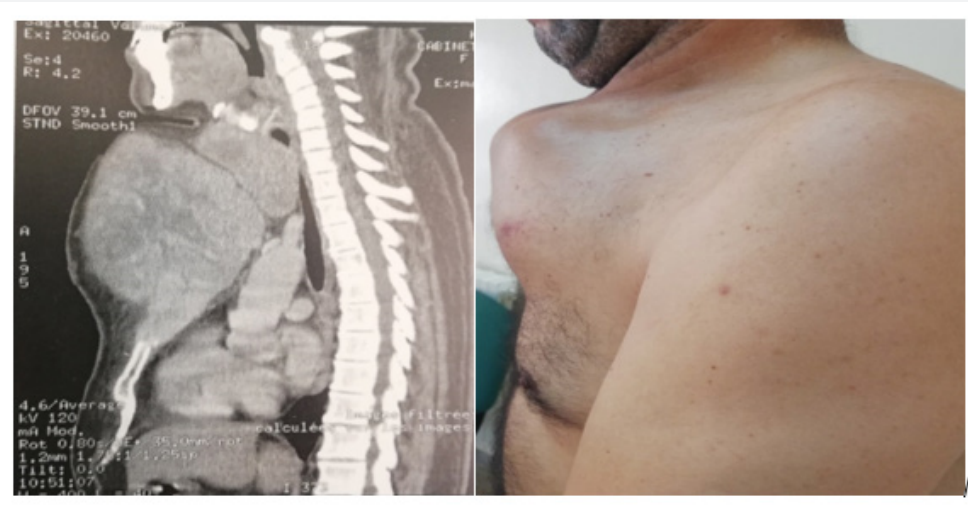

Figure 2: large mediastinal mass resulting in intraoperative cardiac arrest

\section{Observation 4}

75-year-old patient, diabetic on insulin and hypertensive on ARA II, admitted for revascularization of lower limb ischemia under rickets following intraoperative myocardial ischemia revealed by an ST segment underlay and positive troponin dosage (Table 2)

Table 2: Types of intervention, causes and evolution of cardiac arrests in the operating theatre of the Moulay Ismail Military Hospital in Meknes.

\begin{tabular}{|c|c|c|c|c|c|}
\hline & Intervention & ASA & Cause of Cardiac Arrest & Heart Rhythm & Evolution \\
\hline 1 & Volvulus sigmoïde & I & Unknown & QRS larges & Favorable \\
\hline 2 & mass intrathoracique & I & tamponnade & Supraventricular tachycardia & Death \\
\hline 3 & Mediatinal tumour & I & Rhythm disorder And bleeding & Under ST lag & Death \\
\hline 4 & Lower limb ischemia & III & Myocardial infarction & &
\end{tabular}

\section{Discussion}

The occurrence of an ACC during the intraoperative phase is an exceptional but dramatic event. Its management is standardized by recommendations established by the learned anesthesia societies. The etiological diagnosis is often directed by the pre-existing terrain of the patient. However, the etiological investigation must be methodical and systematically include the search for anaphylaxis by the dosage of specific histaminemia, tryptademia and IgE, including in a patient with a major cardiovascular risk [2].

\section{Epidemiology and prognosis}

The incidence of cardiac arrests in the operating theatre has decreased since the publication of the anesthesia safety decree 
that made monitoring, including that of exhaled $\mathrm{CO}_{2}$ and oxygen arterial saturation, mandatory for patients under anesthesia [3]. This incidence is estimated at 5.6 per 10,000 interventions. An intraoperative cardiac arrest can occur at any time of anesthesia and regardless of the technique used. In fact, $23 \%$ of circulatory arrests occur at the time of induction and 29\% during the maintenance of anesthesia. In the case of locoregional anesthesia, the risk of cardiac arrest mainly concerns the installation phase of the anesthesia, with an incidence of 3/10,000 [1]. In patients with coronary artery disease, the incidence of perioperatatory myocardial infarction (IDM) is $4 \%$ for all surgeries combined and varies according to the type of surgery [4].

The risk factors reported are emergency anesthesia, extreme ages of life and a high ASA score. Obstetrics, radiological and diagnostic procedures are associated with an even lower risk. In our study the risk factors found are extreme age in one patient, surgical urgency in one patient, and high-risk surgery in two patients (neoplastic chest surgery).
Poor prognosis factors have been described in terms of survival, such as the starting heart rate (asystolia) and the terrain (congestive heart failure, kidney failure, septicaemia, respiratory failure, high age, major trauma, metabolic abnormality, my line hemorrhageor metastastatic neoplasia) [1].

The prognosis for cardiac arrest in the perioperative period is less bleak than in extrahospital. The survival rate is $31.7 \%$ in in-hospital, while it is $3 \%$ in out-of-hospital. In our study survival was $25 \%(1 / 4)$.

\section{Etiological orientation to perioperative cardiac arrest}

No cause is identified precisely in $10-30 \%$ of cardiac arrests in the operating theatre. In a review of the literature published in 2005, the heart rhythms found on the electrocardiogram are bradycardia in $23 \%$ of cases, asystolia in $22 \%$ of cases, ventricular arrhythmia (FV or TV) in 14\% of cases. ECG is normal in 7\% of cases (33\% undocumented) [1]. The most rediscovered etiologies are mentioned in Table 3.

Table 3: Etiologies Most Commonly Associated with Intraoperative Cardiac Arrest [1].

\begin{tabular}{|c|c|}
\hline Respiratory Causes & $\begin{array}{l}\text { Hypoxia (inhalation, failure of intubation, accidental extubation, pneumothorax, selective intubation, equipment } \\
\text { breakdown, respiratory depression during locoregional anesthesia) Bronchospasm }\end{array}$ \\
\hline Cardiovascular Causes & $\begin{array}{l}\text { Hypovolemic and/or hemorrhagic shock } \\
\text { Surgical manoeuvres associated with decreased organ infusion } \\
\text { Cruoric, gaseous, greasy, cement pulmonary embolism } \\
\text { Hydro-electrolytic imbalance (kaliemia) } \\
\text { Increased intra-abdominal pressure } \\
\text { Transfusion accident } \\
\text { Anaphylactic shock } \\
\text { Pneumothorax compressive } \\
\text { Acute coronary syndrome (infarction, Takotsubo...) } \\
\text { Severe pulmonary arterial hypertension } \\
\text { Pacemaker malfunction } \\
\text { Long Q-T syndrome } \\
\text { Conduction Disorder (Full BAV) } \\
\text { Hypothermia }\end{array}$ \\
\hline Anesthetic Causes & $\begin{array}{l}\text { Overdose of anesthetic agents } \\
\text { Medication errors } \\
\text { Neuraxial anesthesia with brain stem block } \\
\text { Intoxication with local anesthetics } \\
\text { Hyperthermia malignant } \\
\text { Anaphylactic shock }\end{array}$ \\
\hline Neurological Causes & $\begin{array}{l}\text { Stroke } \\
\text { Intracranial hypertension }\end{array}$ \\
\hline
\end{tabular}

\section{Diagnosis, management and resuscitation of circulatory arrest}

The diagnosis of cardiac arrest during anesthesia is quickly made on the basis of the monitoring installed for anesthesia. Notably by the cardioscope, the pulse oxymeter and the monitoring of the exhaled $\mathrm{CO}_{2}[3]$ :

\section{Support}

a) Once the diagnosis of circulatory arrest has been confirmed, especially after checking the reliability of the monitoring, resuscitation should immediately begin with an external or internal cardiac massage (depending on the type of surgery) at a rate of $100 /$ minute [5], trying to minimize the duration and frequency of interruptions. b) The administration of all anesthetic agents must be interrupted during the massage, a purge of the respirator circuits is performed, $\mathrm{FiO}_{2}$ is set to $100 \%$.

c) The patient is of course intubated and ventilated if the procedure was performed under locoregional anesthesia. A reinforcement must be called simultaneously using the emergency procedures of the operating theatre.

d) It should be noted that in the case of ventral decubitus surgery, a cardiac massage in the ventral position should be performed immediately, although its effectiveness is inconsistent and the patient should be placed back in the back position as soon as possible. Further care is codified by SFAR's recommendations: Intravenous adrenaline remains 
the vasopressor of choice, regardless of etiology. The intratracheal pathway is no longer recommended.

In cases of ventricular fibrillation or ventricular tachycardia without a pulse, an external electric shock of 200 joules (8-10 joules internally) must be performed (biphasic defibrillator) followed by a resumption of cardiac massage for 2 minutes before looking for the presence of a rhythm. Amiodarone, lidocaine and magnesium sulphate may be useful for defibrillation-resistant ventricular fibrillations. Infusion solutes must be isotonic.

\section{Etiological diagnosis and specific resuscitation}

The research of the etiology of circulatory cessation is done simultaneously because it can allow to offer a specific treatment essential.

Two approaches can be proposed:

a) The first, described by Moitra et al. [1], is based on the analysis of the starting heart rate. However, this approach is often difficult due to the low specificity of the initial rhythm and a poor analysis of the ECG (parasite) route. b) A second approach is to conduct a series of audits based on the context and frequency of events: The first step is to look for an orientation according to the context: the surgical gesture (hypovolemia, blood loss, gas embolism...), the type of anesthesia (local anesthetic poisoning... ), the terrain (e.g. coronary), the clinic (signs of anaphylaxis...) and finally the data of the monitoring (desaturation, hyperthermia...). Inthe absence of obvious guidance, the search for a ventilatory mechanism is the second step, especially in the intubated patient. Indeed, the most common causes are obstruction or displacement of the intubation tube, bronchospasm and pneumothorax. The slightest doubt about the proper functioning of the ventilation system leads to manual ventilation in pure oxygen.

c) The third step requires a quick check of the anesthesia tray to detect an administrative error;

d) The fourth stage is based on a cardiovascular assessment with analysis of the ECG for a rhythm disorder, a repolarization disorder or conduction. Some studies have analyzed the interest of theinitial cardiacrythmus [1]. (Table 4)

Table 4: Heart Rhythm and Etiology of Cardiac Arrest [1].

\begin{tabular}{|c|c|c|}
\hline \multicolumn{2}{|c|}{ Bradycardia or asystolia } & Tachycardia or Ventricular Fibrillation \\
\hline "H" & « » & \\
\hline $\begin{array}{c}\text { Hypoxia Hypovolemia Hypokalemia Hyperka- } \\
\text { lemia Hydrogen (acidosis) Hypothermia Hypog- } \\
\begin{array}{c}\text { lycemia Malignant Hyperthermia } \\
\text { "Hypervagal" reaction }\end{array}\end{array}$ & $\begin{array}{c}\text { Toxicity (anaphylaxis, anesthesia) } \\
\text { Pneumothorax compressive Thromboembolism } \\
\text { (pulmonary, coronary) Tamponnade Trauma } \\
\text { (haemorrhage) QT elongated }\end{array}$ & $\begin{array}{c}\text { Coronary ischemia } \\
\text { Dyskaliémie }\end{array}$ \\
\hline
\end{tabular}

\section{Main etiologies of intraoperative cardiac arrests}

\section{Acute coronary syndrome and Ischemic heart disease}

Ways to detect ischemic heart events are:

a) ECG changes (T-waves, ST segment, arrhythmias)

b) hemodynamic instability (hypotension, elevated occlusion pulmonary hair pressure);

c) Segmental kinetic disorders visible on transesophageal ultrasound [5].

Most of the time, perioperative infarctions are manifested by sub-shifting of the ST segment, while an extrashift, as reported, is less common. The appearance of intraoperative ST sub-shift is frequently associated with the occurrence of a Q-uniclinked infarction, which evokes a phenomenon of silent ischemia that therefore requires continuous peropoop monitoringofthe ST segment. In perioperative, D01/V02 imbalance is as common as unstable plaque thrombosis. Intracoronarian embolisms and prolonged coronary spasms are rarer causes. However, it has been shown in patients with prior coronary artery disease that perioperative infarction often occurs in a different territory than preoperatively suspected during coronary or stress echocardiography assessment $[5,6]$.

\section{Etiologies of an intraoperative Acute coronary syndrome [5].}

IntraoperativeACS is due to an increase in 02 requirements, the causes of which are

a) Severe aortic stenosis;

b) Severe mitral insufficiency;

c) High blood pressure;

d) tachycardia

e) Or a decrease in 02 intakes due to

f) arteriosclerosis;

g) low blood pressure;

h) Anemia;

i) hypoxemia.

\section{Attitude in case of perioperative ACS}

The goal of the treatment is to reduce Oxygen consumption and increase intakes with $\mathrm{FiO} 2$ to 100\%; ensure noecocodemia; deepen anesthesia and ensure adequate analgesia and monitor hemoglobin levels and transfer if necessary, with a tolerance threshold of $100 \mathrm{~g} / \mathrm{l}$; 
a) administer $500 \mathrm{mg}$ of acetylsalicylic acid (Aspirin $®$ ) if the patient is not already treated, and possibly $180 \mathrm{mg}$ of ticagrelor (to be evaluated according to the type of surgery and anesthetic strategy);

b) beta-blockers in case of tachycardia - $60 \mathrm{~b} / \mathrm{min}$, but only if ventricular function is normal or little impaired

c) infusion nitroglycerin: $0.5-10 \mathrm{~g} / \mathrm{kg} / \mathrm{min}$ (between $1-10 \mathrm{mg} / \mathrm{h}$ ), until pain in the case of ALR disappears;

d) maintenance of coronary infusion pressure unless VG dysfunction: norepinephrine: $0.03-0.5 \mathrm{~g} / \mathrm{kg} / \mathrm{min}$.

In case of cardiogenic shock: catecholamines (dobutamine [Dobutrex®], norepinephrine).

Intra-aortic counterpulsion balloon if amines are ineffective.

The assessment should be completed as soon as possible with an ECG 12 bypass, a dosage of cardiac enzymes and an echocardiography; again, it is necessary to be able to recognize an SCA with sus-shifting ST that requires revascularizationas soon as possible [5]. The 2004 ACC/AHA recommendations state that in the face of an IDM with a sus-shift of the ST segment (STEMI) complicated by cardiogenic shock, an emergency revascularization must be carried out as soon as possible, either by percutaneous angioplasty or by fibrinolysis [3]. However, in a perioperative context, fibrinolysis is naturally contraindicated due to hemorrhagic risk and only coronary angioplasty can be proposed, with hemorrhagic problems related to anti-stick antiaggregatersand anticoagulation [6].

\section{Perioperative rhythm disorders}

Rhythm disorders associated with anesthetic agents are among the well-known side effects in general anesthesia. Long QT (QTL) (according to Bazett's formula) is defined by: QTc $440 \mathrm{~ms}$ (severe if $500 \mathrm{~ms}$ ), this parameter is a known risk factor for spike twisting, which can lead to ventricular fibrillation and circulatory arrest. Moreover, this phenomenon is all the more formidable because significant variations in QT have been demonstrated in the postoperative period [7] (Figure 2).

\section{Intraoperative anaphylactic shock}

The incidence of peraphylactic allergic or anaphylactic (AA) accidents varies from one in 3,500 to one in 13,000 studies. In children, the incidence is estimated at 1 in 7741 for all types of anesthesia combined. The main substances responsible are latex, curares,ntibiotics and hypnotics [8]. InMorocco, no prospective studies have looked at this impact. The results obtained are most often derived from an estimate, the result of a simple evaluation based on retrospective studies. This incidence is in the order of 1 in 4970. Moreover, there are few systematic studies linking the dual epidemiological aspect (frequency, risk factors) and osotic etiool(responsible drug).

General anaphylaxia (GA) are severe accidents that can be fatal. Mortality is estimated at between $2 \%$ and $6 \%$. All anesthetic agents may be involved. In France, curares are the most blamed, with rates between 49.6 and $81.0 \%$ according to studies [9].

Curares are the leading cause of intraoperative anaphylaxis in countries such as France, Norway, Spain and Australasia [10]. Responsibility for other causes such as antibiotics, latex is called into question [11].

The symptomatology varies depending on the severity. In intraoperative, cardiovascular signs (hypotension, tachycardia, arrhythmia.) appear with or without skin signs. These can be masked by surgical draping. The presence of bronchospasm is less frequent and unspecific, especially during general anesthesia [11]. The clinical signs observed are the same for both types of reactions (IgE dependent or not). These signs are not always complete and the absence of skin-omu signsdoes not exclude diagnosis [9].

Independent risk factors for fatal anaphylaxis were male, cardiovascular disease, b-blockersat the time of reaction, and injection of the muscle relaxant in an emergency. The type of curare administered was not one of them, a controversial observation because other series show discordant results. In the case of death, the average time to experience shock after curare injection was $2.27 \mathrm{~min}$ (1-5) and the average dose of adrenaline administered was $15.34 \mathrm{mg}(1-60)$ [10].

\section{The diagnostic approach}

The diagnostic assessment seeks to prove a dependent IgE reaction, the role of the suspect product and possible crossawareness. The immediate investigation is based mainly on the dosage of serum tryptase, with three samples needed in the acute phase. A remote sample of the reaction is required to interpret the small increases. The dosage of plasma histamine levels is also part of the immediate balance sheet. Concordance with tryptase concentrations is generally good, but some patients have only an increase in histamine concentration and others only tryptase. Histamine appears more sensitive than tryptase in moderate reactions. The association of histamine and tryptase dosages increases diagnostic sensitivity [9].

The subsequent investigation is carried out as part of an allergo-anaesthesia consultation. The balance includes the dosage of specific IgE with skin tests (prick-tests then IDR) and will concern curares, hypnotics and morphinics. If skin tests quantify the IgE attached to the skin mast cells, the IgE dosage evaluates serum free IgE. Specific IgEs concern quaternary antiammoniums in the case of curares [9]. The management of anaphylactic shock iswell codified. It must be started early. Treatment consists of stopping the administration of any medication, the momentary cessation of the intervention, the administration of pure oxygen, vascular filling with crystalloids and the administration of vasopresand and corticosteroids [11] For vasopressors, adrenaline is the first-line drug. It is recommended to adapt adrenaline doses to the hemodynamic response by rereading a titration until the correct blood pressure is restored. Doses of 1 to $10 \mathrm{ug} / \mathrm{kg}$ can be relayed by a continuous infusion started at $0.1 \mathrm{mg} / \mathrm{kg}$ per minute. 
Glucocorticoids are often given in the acute phase of anaphylactic shock, although their effects are delayed by several hours. After hemodynamic stabilization, a biological check-up should be done quickly involving a dosage of histamine and tryptase $[12,13]$.

\section{Prevention}

Primary prevention consists of patients not being exposed to drugs that may induce immediate hypersensitivity in intraoperatively. This concept is difficult to achieve with general anesthetics [9].

Secondary prevention consists of not reexposing the patient to a product against which he is sensitized, hence the interest of the systematic allergological investigation after an immediate hypersensitivity reaction during an AG. It is noted here that premedication in this case has been ineffective. Better yet, locoregional anesthesia should be preferred and myorelaxation should be avoided when it is not justified (digestive endoscopy, ENT surgery,etc.) [9]. Peraesthetic allergic reactions are a reality in the Moroccan context, hence the interest in expanding this study to other services, and in raising awareness among anaesthetists of the practice of systematic blood samples during a reaction. hypersensitivity, and then refer patients to the allergoanaesthesia consultation.

The latest SFAR/SFA recommendations "preventing allergic risk in anesthesia" will help to raise awareness among different specialists (anaesthetists, surgeons, allergists) and to harmonize procedures [9].

\section{Epidemiology of curare allergies}

Epidemiological data on allergic perioperative complications in France show that curares are the drugs that induce the greatest number of anaphylactic reactions. The curares most frequently involved were suxamethonium (68.2\%) and atracurium (13.9\%), followed by rocuronium (10.6\%) [10-14].

\section{Pathophysiological mechanisms of reactions to curares}

Curares can induce genuinely allergic reactions (type I, IgE-mediated) or by nonspecific histaminolibération. The latter is referred to as a differential diagnosis before a negative allergological assessment [10].

\section{Severity of allergic reactions to curares}

Clinical symptomatology alone does not direct suspicion towards one molecule over another. Nevertheless, allergic reactions to curares are considered severe (anaphylactic), and rapid, typically occurring at the induction of anesthesia, within seconds or minutes after intravenous administration of muscle relaxants [10].

\section{Hypersensitivity reactions of propofol}

Diprivan is composed of propofol, refined soybean oil and purified egg phosphatide. The incidence is estimated at one in 60,000 cases and represents $1.2 \%$ of perioperative hypersensitivity reactions in France. Several teams report cases of hypersensitivity to propofol, including one in a child allergic to peanuts. Peanuts and soybeans belonging to the same botanical family, legumes, are similar from aphylogenetic and antigenic point of view [8]. Cases of propofol-induced bronchoconstriction in patients with a history of rhinitis printanière are also reported. When injecting Diprivan, a hypersensitivity reaction may be related to cross-reactivity [8]

\section{Prevention of propofol allergy}

Given the data currently available, it seems appropriate to avoid propofol in patients with an isolated peanut allergy or an asthma allergic to birch pollen, given the increased risk of crossallergy with It's Diprivan. It seems desirable to propose either locoregional anesthesia when it is feasible or general anesthesia by favouring other hypnotics such as halide or etimidate. These patients may also be discussed with an allergo-anesthesy consultation to test for soy [8].

Hypersensitivity reactions (HS) to betalactamines (BL) were described shortly after the commercialization of penicillins and then with the other BL groups immediately put on the market. It is classically accepted that nearly $10 \%$ of subjects treated by BL report suspicious allergic reactions. These reactions account for $25-45 \%$ of all suspected allergic drug side effects, significantly outpacing all other drug classes. However, it is currently shown that more than $80 \%$ of suspected penicillin-allergic subjects are not actually allergic [15]. The frequency of patients with a clinical history of penicillin allergy varies from 1 to $10 \%$ depending on the studies. Penicillin G has long been considered the most fusing BL for allergic reactions. However, recent data suggest that amoxicillin $(\mathrm{AX})$ is increasingly involved due to the reversal of the prescribing trend in its favor [15].

\section{AA symptomatology in $\mathrm{BL}$}

Anaphylactic shock occurs in $0.2 \%$ of cases with a mortality of $0.02 \%$. It is estimated, however, that the number of deaths secondary to an anaphylactic reaction to BL accounts for $75 \%$ of fatal drug shocks [15]

Several hypotheses may explain the presence of specific IgE several years after the last therapeutic exposure to penicillins:

a) Natural persistence of penicillin-specific IgEs.

b) Some patients have very strong immunological memory and the secretion of antibodies by plasma cells can last for years after antigenic stimulation;

c) Occult exposure to food penicillins;

d) Skin or mucous contact with penicillins;

Cross-reactivity with environmental allergens/molecules. Occult exposures to penicillin during ingestion of milk or meat have been reported to cause allergic skin manifestations and respiratory problems. It is also possible that the patient may 
have come into contact with low doses of penicillin, such as those that can be exposed to when preparing an amoxicillin drinkable suspension for the treatment of infections in his children. Finally, cross-reactivity against infectious agents or environmental molecules is possible, as suggested in the case reported by Guillet et al. of a subject who developed hives and anaphylactic shock from food allergy to Penicillium italicum [16].

\section{Differential diagnosis and assessment of the severity of anaphylactic shock}

Cardiovascular manifestations of anaphylaxis and anaphylactic shock may be confused with several other pathologies with a similar clinical picture (Table 2) when skin or bronchopulmonary signs suggestive of anaphylaxis are absent [17].

Differential diagnosis of anaphylactic shock. [17].
a) Heart events
b) Anesthetic overdose
c) Activation vagale (syndrome vasovagal)
d) Cardiac arrest of other etiologies
e) Syndrome carcinoïde
f) Massive pulmonary embolism
g) Respiratory protests
h) Obstruction of upper airways
i) Intrabronchic foreign body
j) Bronchospasm
k) Asthma malcondition
l) Spontaneous Pneumothorax

\section{Should the intervention be continued?}

In the event of an effective cardiac activity, the decision to postpone or continue the surgical procedure should be discussed on a case-by-case basis. Several factors fuel the discussion: the indication of the intervention and its vital nature, whether it is started or not, the degree of urgency, the etiology and duration of cardiac arrest, and the hemodynamic stability after cardiac arrest. If the procedure is not started and it is not vital, it must be postponed. If it is in progress, it is completed or shortened if possible [1].

In our study the procedure was delayed for a patient who had a delayed and shortened emergency in a patient who had a chest mass compressing the heart.

\section{References}

1. Diane Lena-Quintard (2015) Cardiocirculatory arrest at cardiac arrest in the operating room. The Resuscitation Anesthesia Practitioner 19: 136-142.

2. V Muller, E Morell, C The Marec, P Pasquier, JM Rousseau (2010) Cardiac arrest at the induction of a patient into thyrotoxicosis. Have you thought about anaphylaxis? Ann Fr Anesth Reanim 29(6): 488-490

3. Otteni JC, Benichou A, Bricard H, Caramella JC, Clergue F, et al. (1994) Recommendations for monitoring patients under anesthesia. SFAR.

4. Ashton CM, Petersen NJ, Wray NP, Kiefe CI, Dunn JK, et al. (1993) The incidence of perioperative myocardial infarction in men undergoing noncardiac surgery. Ann Intern Med 118: 504-510.

5. PG Chassot, MA Bernath, X Lyon, E Albrecht. Cardiovascular system and anesthesia.

6. N Mottard, JS David, N Mewton, M Abdellaoui, A Cheron, et al. (2009) Intraoperative myocardial infarction, what management in the acute phase? Clinical case. French Annals of Anesthesia and Resuscitation 28: 692-696.

7. T Leclercq, S Parrel, S Mierdl, Y Cottin, C Girard (2014) Clinical case: Acquired long QT syndrome and general post-aneaesthesia cardiorespiratory arrest. About a case and review of the literature. French Annals of Anesthesia and Resuscitation 33: 421-426.

8. M Fontaine, J Dubost, F Bienvenu, R Ferrenq Dubost, G Proton, et al. (2011) the galenic form of propofol used in the establishment. Severe Bronchospasm with Diprivan1 in a child allergic to peanut and birch pollen. French Annals of Anesthesia and Resuscitation 30: 147-149.

9. Elftouh, K Bouti, E Ardouz, R Moussaoui, MT El Fassy Fihry, et al. (2012) Allergies to general anesthetics. Results of an investigation at the IbnSina Hospital in Rabat. French Journal of Allergology 52(5): 371-374.

10. Chiriac AM, Demoly P (2016) Allergy and curares. Press Med 45(9): 768-773.

11.Ziadi A, Ejlaidi A, Hachimi A, Elkhayari MA, Samkaoui (2014) Intraoperative cardiac arrest of a surgery of a hydatic liver cyst. Ann Fr Anesth Reanim 33(3): 195-196.

12. French Society of Anaesthesia and Resuscitation (SFAR), FrenchSociety of Allergology (SFA) (2011) Expert formalized recommendationsPrevention of peraesthetic allergic risk. Ann Fr Anesth Reanim 30: 212-22.

13. Longrois D, Lejus C, Constant I, Bruyre M, Mertes PM (2011) Formalised expert recommendations. Treatment of anaphylactic reactions during anesthesia and in particular anaphylactic shock. Ann Fr Anesth Reanim 30: 312-322.

14. C Rocchiccioli, R Aldea, MT Guinnepain, Mr Fischler (2009) Anaphylactic shock due to complicated succinylcholine of rhabdomyolysis. Ann Fr Anesth Reanim 28(9): 787-789.

15. A Chaabane, K Aouama, NA Boughattas, Mr Chakroun (2009) Allergy to betalactamines: myth and realities. Med Mal Infect. 39(5): 278-287.

16. A Bernède, P Pralong, C Cherh, AL Breton, JF Nicolas, et al. (2014) Amoxicillin anaphylaxis 31 years after theprevious accident. French Journal of Allergology 54: 451-453.

17. D Longrois, C Lejus, I Constant (2011) Prevention of peraesthetic allergic risk. French Annals of Anesthesia and Resuscitation 30: 212222. 
This work is licensed under Creative Commons Attribution 4.0 License

DOI: 10.19080/JAICM.2019.09.555779
Your next submission with Juniper Publishers will reach you the below assets

- Quality Editorial service

- Swift Peer Review

- Reprints availability

- E-prints Service

- Manuscript Podcast for convenient understanding

- Global attainment for your research

- Manuscript accessibility in different formats ( Pdf, E-pub, Full Text, Audio)

- Unceasing customer service

Track the below URL for one-step submission https://juniperpublishers.com/online-submission.php 